\title{
Previously unreported abnormalities of dermal basement membranes and collagen fibrils in a patient with X-linked spondyloepiphyseal dysplasia tarda
}

\author{
D.Q. Borsey ${ }^{1}$, D. Hopwood ${ }^{2}$, A.J. Montgomery ${ }^{1}$, D.B. Walsh ${ }^{3}$ and R.T. Jung ${ }^{1}$ \\ Departments of ${ }^{1}$ Medicine, ${ }^{2}$ Pathology and ${ }^{3}$ Clinical Biochemistry, Ninewells Hospital and Medical School, Dundee \\ DD1 9SY, Scotland, UK.
}

\begin{abstract}
Summary: Electron microscopic findings of the skin biopsy of a boy with spondyloepiphyseal dysplasia tarda showed several novel features. The basement membrane of the epidermis showed focal irregular thickening and reduplication. The collagen fibres showed foci of fibrous long spacing collagen and marked variation in fibre diameter. Taken together these abnormalities have not been reported in any other condition.
\end{abstract}

\section{Introduction}

The spondyloepiphyseal dysplasias are a group of inherited disorders characterized by primary and usually progressive abnormalities of vertebral and epiphyseal development (Spranger \& Langer, 1974). We report a patient with 'classical' X-linked recessive spondyloepiphyseal dysplasia tarda (SEDT) in whom abnormalities of both collagen fibrils and basement membranes were found on electron-microscopic examination of a skin biopsy.

\section{Patient and methods}

A boy aged 14 years and 2 months was referred because of short stature. At presentation he was $138.5 \mathrm{~cm}$ (54.0 inches; < 3rd centile) in height and weighed $35.0 \mathrm{~kg}(77.0 \mathrm{lb} ; 3 \mathrm{rd}-10$ th centile). The mean parental height was between the 10th and 25 th centiles at $171.5 \mathrm{~cm}$ (67.0 inches). The patient's sitting height was $66.0 \mathrm{~cm}$ (25.7 inches) and subischial height $72.5 \mathrm{~cm}$ (28.3 inches). His height velocity over the 15 months following the above assessment was $2.9 \mathrm{~cm} /$ year (3rd-10th centile). He had a barrel shaped chest with prominence of the sternum, a narrow pelvis, slight webbing of the neck and a marked dorsal kyphosis with an accentuated lumbar lordosis. Genital development and pubic hair growth were at Tanner stage 2, and testicular volume was $3 \mathrm{ml}$ bilaterally. Slit lamp examination of the eyes demonstrated no lens

Correspondence: R.T. Jung, M.A., M.D., F.R.C.P.E. Accepted: 30 April 1986 opacities. His brother, aged 24 years, apparently had a similar appearance and at the age of 12 years had been diagnosed as having a forme fruste of Morquio-Brailsford disease, although his urinary mucopolysaccharides were normal. A sister aged 21 years was normally developed.

The patient's serum total thyroxine level was $129 \mathrm{nmol} / 1$ (normal range: $75-145 \mathrm{nmol} / \mathrm{l}$ ) and testosterone $3.3 \mathrm{nmol} / 1$. Serum growth hormone rose from a basal value of $5.4 \mathrm{mU} / 1$ to $26 \mathrm{mU} / 1$ on strenuous ergometric cycling. Bone age (Tanner Whitehouse 11) on presentation was 12.4 years. Urinary mucopolysaccharides (glycosaminoglycans) were normal at $60 \mathrm{mg} / \mathrm{g}$ creatinine. Two dimensional electrophoresis of extracted urinary mucopolysaccharides and thin-layer chromatography for oligosaccharides showed normal patterns. Reilly bodies were absent in blood smears. Serum lysosomal hydrolases were normal. A $75 \mathrm{~g}$ oral glucose tolerance test was normal. Radiology confirmed the diagnosis of SEDT (Maroteaux et al., 1957). There was an increased antero-posterior diameter of the chest and narrow pelvis. The pelvic radiograph showed that the iliac rings were small and the acetabulae deep. The lower thoracic and lumbar vertebrae had a flattened appearance (platyspondylia) with characteristic bioconvexity of the central and posterior aspects of the superior and inferior plates. Anteriorly the vertebral bodies were constricted resulting in a 'cod's mouth' appearance (Figure 1).

A skin biopsy was taken from the forearm. Fibroblast culture from this specimen showed normal $\beta$-galactosidase $(778 \mu \mathrm{mol} / \mathrm{gh}$; normal range $=$

(C) The Fellowship of Postgraduate Medicine, 1986 


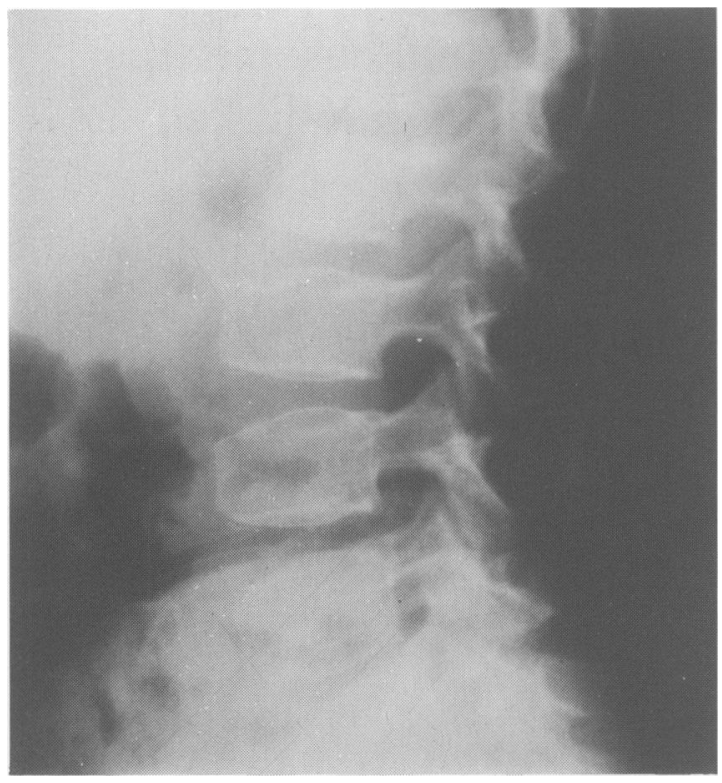

Figure 1 Radiograph of lumbar spine of the patient showing platyspondylia, biconvexity of the central and posterior aspects of the superior and inferior plates. Anteriorly the vertebral bodies show the 'cod's mouth' appearance.

$400-1399)$ and $\beta$-hexosaminidase $(9526 \mu \mathrm{mol} / \mathrm{gh}$; nor$\mathrm{mal}=6000-12000$ ) activity. Electron microscopy was carried out on the glutaraldehyde-fixed specimen.

\section{Results}

Electron microscopy showed a number of features in the patient's skin biopsy which were unusual. The most noticeable were related to the basement membrane of the epidermis and the sweat glands. There were focal irregular thickenings up to $2.5 \mu \mathrm{m}$ (Figure 2). This was due to fibrillary material deposited in an apparently random manner between two morphologically otherwise normal laminae densae. Where there was a gap in the mesenchymal lamina densa, the sandwiched fibrils spilled over. The lamina lucida of the basement membrane showed no obvious abnormalities. The mesenchymal lamina densa contained numerous anchoring fibrils, some of which showed loop forms. These formed the sublamina densa area, the other abnormality of the basement membrane being its reduplication which again was focal (Figure 3). The epithelial hemidesmosomes were abundant. The basement membranes around other mesenchymal structures showed no abnormality.

The other abnormalities were related to collagen

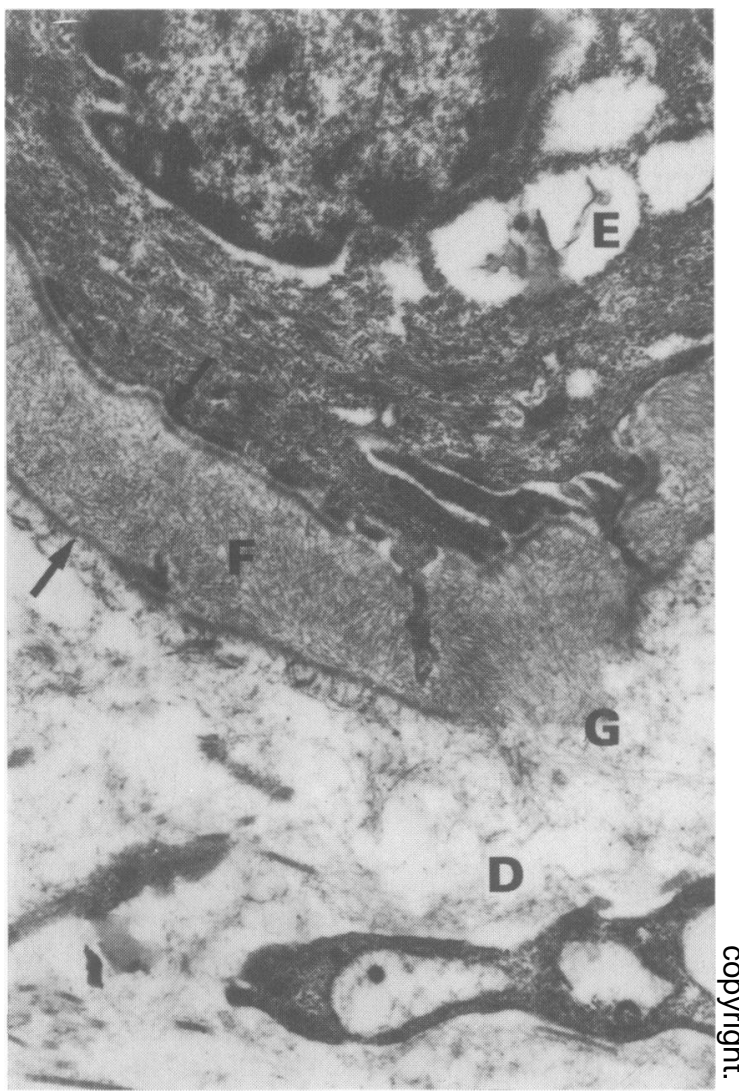

Figure 2 The basement membrane shows foci of widening (arrows) due to deposition of fibrillary materials (F). These spill out into the connective tissue space where there is a gap $(G)$ in the mesenchymal basement membrane. $\mathrm{E}=$ epidermis; $\mathrm{D}=$ dermis; $\times 17,300$.

fibres. The most striking of these were the foci of fibrous long spacing collagen which were not related to any particular structures (Figure 4). The other feature was the variation in the diameter of the collagen fibres which otherwise had normal periodicity. The collagen fibres in our patient had a significantly higher mean diameter $(57 \mathrm{~nm} ; 1 \mathrm{s.d}$. was 12; Student's 2 sample $t$-test: $t=4.6, P<0.001)$ and a significantly greater range of diameters $(40-80 \mathrm{~nm} ; \mathrm{F}$ test for equality of variances: $\mathrm{F}=2.02, P<0.05)$ than those seen in a normal subject $(48 \pm 8 \mathrm{~nm}$; range 30-70 nm) (Wetherill \& Barrie, 1982).

\section{Discussion}

There have been no previous reports of electron microscopy findings in patients with classical X-linked 


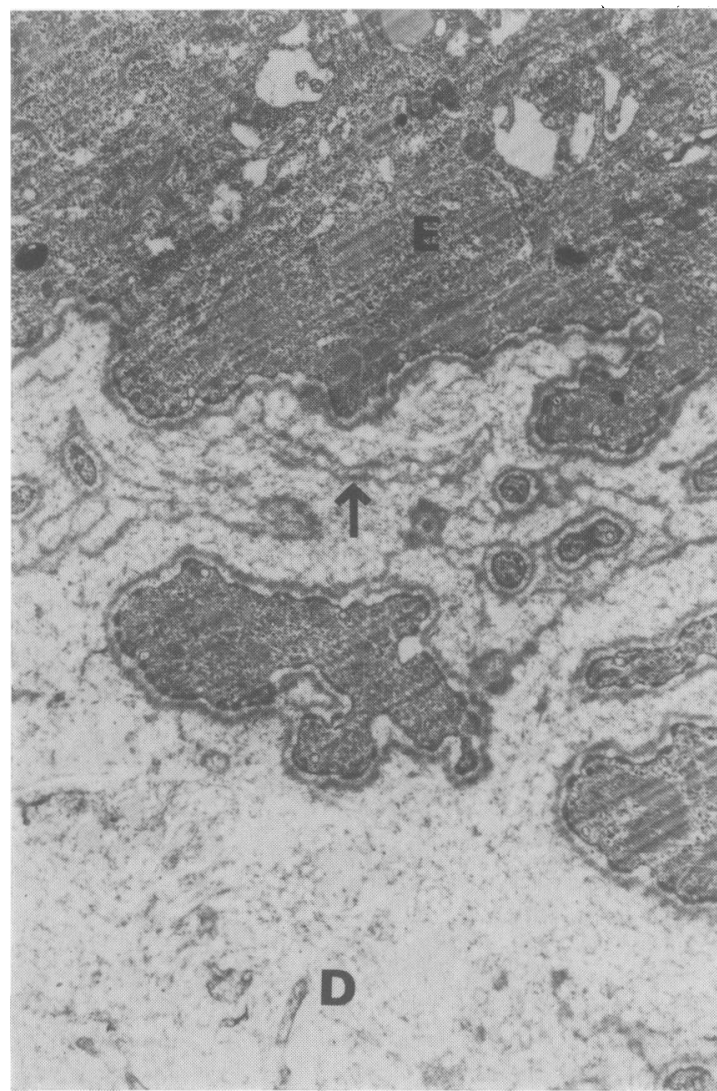

Figure 3 Basement membrane with marked reduplication (arrowed). $\mathrm{E}=$ epidermis; $\mathrm{D}=$ dermis; $\times 13,000$.

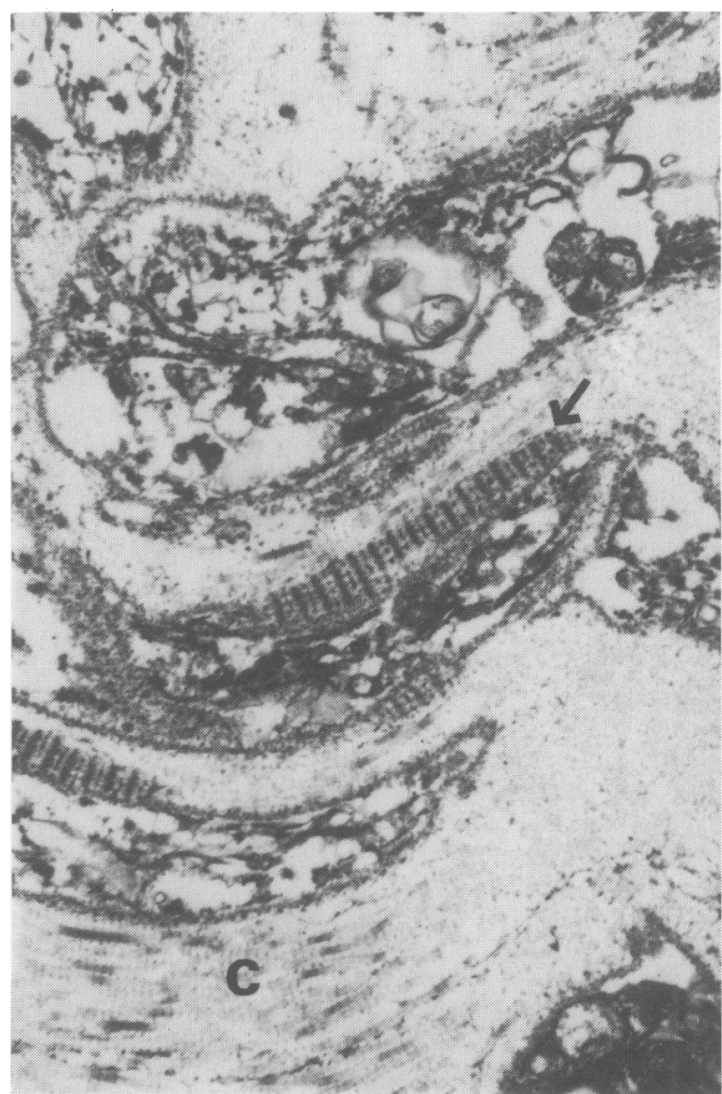

Figure 4 Fibrous long spacing collagen (arrowed) elsewhere morphologically normal collagen is formed $(-\mathrm{C}) . \times 18,000$.
SEDT (Type A). However, in 1978, Byers and colleagues described a new variety of SEDT (Type D) characterized by punctate corneal dystrophy, soft skin, mild hypermobility of the small joints and early onset osteoarthritis in which the dermal collagen on electron microscopy revealed areas of disorganized collagen fibrils interspersed with apparently normal fibrils (Byers et al., 1978a, b). The atypical collagen contained fibrils which were coiled, folded back on themselves and partially dissociated into finer component elements. They also reported that banding pattern was completely lost in some of the collagen, whilst in others it was preserved for a portion of the fibril length. Also, biochemical data from dermal fibroblast culture was reported as demonstrating abnormal proteoglycan metabolism. In our case, however, the electron microscopy features were different and fibroblast culture showed normal levels of $\beta$-galactosidase and $\beta$-hexosaminidase.

The normal structure and histochemistry of epidermal basement membranes has been reviewed recently by Katz (1984) in relation to skin disease. The lamina lucida contains laminin and bullous pemphigoid antigen which we were unable to investigate due to the fixation of the specimen. In our case, the lamina densa was morphologically normal with regard to the investigations we were able to pursue; it is known to contain collagen VI and proteoglycans. The thickened basement membrane found in our case has also been reported in a variety of diseases, for example, collagenous colitis, capillary basement membranes in diabetes mellitus and a number of renal conditions (Gledhill \& Cole, 1984; Meadows, 1978; Williamson \& Kilo, 1977). In diabetes mellitus the capillary basement membranes gradually increase with age whereas in scleroderma there is a deposition of fibrillary material 
deep to the epidermal basement membrane with the perturbation of the anchoring fibrils. The thickening in the dermal basement membrane with our patient does not fit into any of these categories.

Reduplication of the basement membrane as found in our case has also been described in a number of pathological conditions. Some of these are related to chronic inflammation of such tissues as gingiva (Takarada et al., 1974) and the gallbladder (Hopwood $e t$ al., 1980). It has also been described in cholestatis (Sasaki et al., 1967). Although native collagen normally forms with a characteristic periodicity of approximately $67 \mathrm{~nm}$, fibrous long spacing collagen, a feature of our biopsy, may also be found in normal human tissues such as Descemet's membrane (Jakus, 1962). It can also occur in a number of pathological lesions including various skin diseases such as lepromatous

\section{References}

BYERS, P.H., HOLBROOK, K.A., HALL, J.G., BORNSTEIN, P. \& CHANDLER, J.W. (1978a). A new variety of spondyloepiphyseal dysplasia characterised by punctate corneal dystrophy and abnormal dermal collagen fibrils. Human Genetics, 40, 157.

BYERS, P.H., HOLBROOK, K.A., CHANDLER, J.W., BORNSTEIN, P. \& HALL, J.G. (1978b). Electron microscopy as an aid to diagnosis of disorders of the extracellular matrix: a new type of spondyloepiphyseal dysplasia. Birth Defects, 14, 221.

EDWARDS, R.P. (1975). Long spacing collagen in skin biopsies from patients with lepromatous leprosy. British Journal of Dermatology, 93, 175.

GLEDHILL, A. \& COLE, M.F. (1984). Significance of basement membrane thickening in the human colon. Gut, 25, 1085.

HASHIMOTO, K. \& OHYAMA, H. (1974). Cross banded filamentous aggregation in the human dermis. Journal of Investigative Dermatology, 62, 106.

HOPWOOD, D., KOUROUMALIS, E., MILNE, G. \& BOUCHIER, I.A.D. (1980). Cholecystitis: a fine structural analysis. Journal of Pathology, 130, 1.

JAKUS, M.A. (1962). Further observations in the fine structure of the cornea. Investigative Ophthalmology, 1, 202.

KATZ, S.I. (1984). The epidermal basement membrane: leprosy (Edwards, 1975), scleroderma (Kobayashi \& Asboe-Hansen, 1972), basal cell and squamous carcinoma (Hashimoto \& Ohyama, 1974).

Nevertheless, our patient's structural abnormalities would appear to be a distinct entity since, besides thickening and reduplication of the basement membrane with fibrous long spacing collagen, there were differences in diameter of the collagen fibres and a perturbation of the basement membrane which, as a complex, are not seen in any other condition.

\section{Acknowledgements}

Our thanks to Dr Brian Fowler of Willink Biochemical Genetic Laboratory, Royal Manchester Children's Hospital, for the report on $\beta$-galactosidase and $\beta$-hexosaminidase.

structure, ontogeny and role in disease. Basement Membranes and Cell movement. Ciba Symposia, 108, 243. Pitman: London.

KOBAYASHI, T. \& ASBOE-HANSEN, G. (1972). Ultrastructure of generalised scleroderma. Acta Dermato-Venereologica, 52, 81.

MAROTEAUX, P., LAMY, M. \& BERNARD, J. (1957). La dysplasie spondyloepiphysaire tardive; description clinique et radiologique. Presse médicale (Paris), 65, 1205.

MEADOWS, R. (1978). Renal Histopathology, 2nd ed. Oxford University Press: Oxford.

SASAKI, H., SCHAFFNER, F. \& POPPER, H. (1967). Bile ductules in cholestasis. Laboratory Investigation, 16, 84.

SPRANGER, J. \& LANGER, L.O. (1974). Spondyloepiphyseal dysplasias. Birth Defects, 10, 19.

TAKARADA, H., CATRONI, M., SAGIMOTO, A. \& ROSE, G.G. (1974). Ultrastructural studies of human gingiva. III Changes of the basal lamina in chronic periodontitis. Journal of Periodontology, 45, 288.

WETHERILL, D. \& BARRIE, G. (1982). In Elementary Statistical Methods, p. 160. Chapman and Hall: London.

WILLIAMSON, J.R. \& KILO, C. (1977). Current status of capillary basement membrane disease in diabetes mellitus. Diabetes, 26, 65. 